\title{
Intelligent control of flywheel energy storage system associated with the wind generator for uninterrupted power supply
}

\author{
Bensaid Amel $^{1}$, Zebirate Soraya ${ }^{2}$, Chaker Abdelkader ${ }^{3}$ \\ 1,2,3 SCAMRE Laboratory, Maurice Audin, National Polytechnic School of Oran, ENPO, Oran, Algeria \\ ${ }^{2}$ IMSI, University of Oran 2 Mohamed BENAHMED, Oran, Algeria
}

\begin{tabular}{l} 
Article Info \\
\hline Article history: \\
Received Dec 4, 2019 \\
Revised Apr 26, 2020 \\
Accepted Jul 17, 2020 \\
\hline Keywords: \\
Doubly fed induction generator \\
Flux-oriented control \\
Flywheel energy storage system \\
Fuzzy logic controller \\
Power control \\
Variable speed wind generation
\end{tabular}

\begin{abstract}
Wind energy is currently the fastest-growing energy source in the world. However, the inherent characteristic of intermittent energy production, due to the stochastic nature of wind, still comprises the main drawback of wind power. To avoid such problems, various configurations have been reccomended in order to reduce output power variation. The paper concentrates on performance benefits of adding energy storage system with the wind generator in order to regulate the electric power delivered into the power grid. Compared with other means of energy storage, the flywheel energy storage system (FESS) is the best choice to solve power quality problems. In this paper, a FESS associated to a variable speed wind generation (VSWG) is investigated by presenting two control strategies applied to the storage system equipped with an induction machine; both techniques are studied and developed and consist of a field control (FOC) and a Fuzzy Logic Control (FLC). Simulation model is established in MATLAB/Simulink and comparative results are then reported.
\end{abstract}

This is an open access article under the CC BY-SA license.

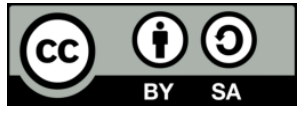

\section{Corresponding Author:}

Bensaid Amel,

Department of Electrical Engineering,

SCAMRE Laboratory, Maurice Audin National Polytechnic School ENPO, Oran, Algeria

ENP of Oran, BP 1523 El Mnaouer, Oran, Algeria.

Email: bensaid.amel@gmail.com

\section{INTRODUCTION}

In recent years, wind energy has been the fastest growing and most profitable source of renewable energy. Nevertheless, the inherent characteristic of intermittent energy production, due to the highly fluctuating and unpredictable character of the wind, still remains the major inconvenient to a wind power. Due to the rapid increase in the number of wind farms connected to the network, the variable power produced has negative effects on the stability and power quality of the connected electrical equipments [1]. To overcome this drawback, various configurations have been reccomended in order to regulate the power flow between the wind generator and the power grid. A practical solution consists on introducing an energy storage element in connection to a wind power. There are several methods of energy storage that can be differentiated into two categories [2]; Long term storage holds energy over a duration ranging from weeks to a year such as pumped storage hydropower [3], electrochemical [4], and compress air energy storage [5]. Short term storage applies to storage over a duration ranging from several minutes to a few days, such as superconducting magnetic energy storage [6], capacitance electric field energy storage [7] and flywheel energy storage $[8,9]$. The ever-increasing amount of attention on electrochemical energy storage compared with other storage systems, but, since rapid response is necessary to compensate power variations in short period, they are not appropriate to be associated with WT due to their chemical process. The superconductor 
coils and the super-capacitors are still under development so they are very expensive [10]. However, The inertial storage system by its special features such as low cost, high reliability ,good efficiency, large energy storage capacity, rapid response and its long lifetime which is similar to the wind generators; remains the most suitable system for storing wind energy. [11-13] prove that the FESS presents an interesting solution for adjusting production to consumption. Consequently, when there is an increase in the generated power compared to the demanded power, the difference is stocked in the FESS via the electric machine that is used as a motor. Inversely, when an imbalance occurs in the power system, the process is reversed and the flywheel releases its energy and the machine uses as a generator carrying the network.

The theory of vector control, applied to the IM of FESS in [14, 15] successfully led to a powerful tool for its control. However, experience has highlighted some weaknesses of this method against disturbances due to uncertainties of the parameters. It becomes important to use a robust control method, insensitive to parameter variations, disturbances and non-linearities. Thus, an intelligent controller such as fuzzy controller is needed for improving the speed response; it incorporates human intelligence into the process control application which can give better dynamic response of the system [16]. In this paper, a low-speed FESS coupled to a VSWG is explored. Figure 1 illustrates a schematic diagram of the FESS - VSWG combination under study, where the power generation and storage energy can be linked to each other via a DC bus. in such setup, the inertiel storage system guarantees the voltage control of the dc link, hence making balance between production and consumption energy. The FESS concerned includes a low speed flywheel and squirrel cage induction machine, the latter operates in the area of weakening flux, therefore permitting operation at rated power, we present another method control to the FESS, i.e. the Fuzzy logic Controller with good comparisons between FOC and FLC are given. The VSWG used is based on a DFIG where its stator is directly connected to the grid and its rotor is connected to the grid by power converters. To study the power transfer between the wind turbine and the grid, we have used an independent power control. So, there were two control blocks (FESS control and DFIG control) in the device under study. The first is derived to control the energy storage in the flywheel, the second is derived to control the active and reactive power exchanged between the network and DFIG. These two blocks may be separately controlled. A MATLAB simulation model has been developed to verify the successful working of the considered system, in terms of dynamic response and output power smoothing.

We have organised the rest of this paper in the following way: Section 2 shows the modelling of the FESS (Flywheel, Mechanical shaft and IM modeling). The considered methods of control strategies for the FESS (FOC and FLC) are described in more detail in Section 3. Subsequently, Wind turbine modeling (turbine, DFIG and Power control of DFIG). Section 5 presents results and analysis. Finally, conclusion is given in Section 6.

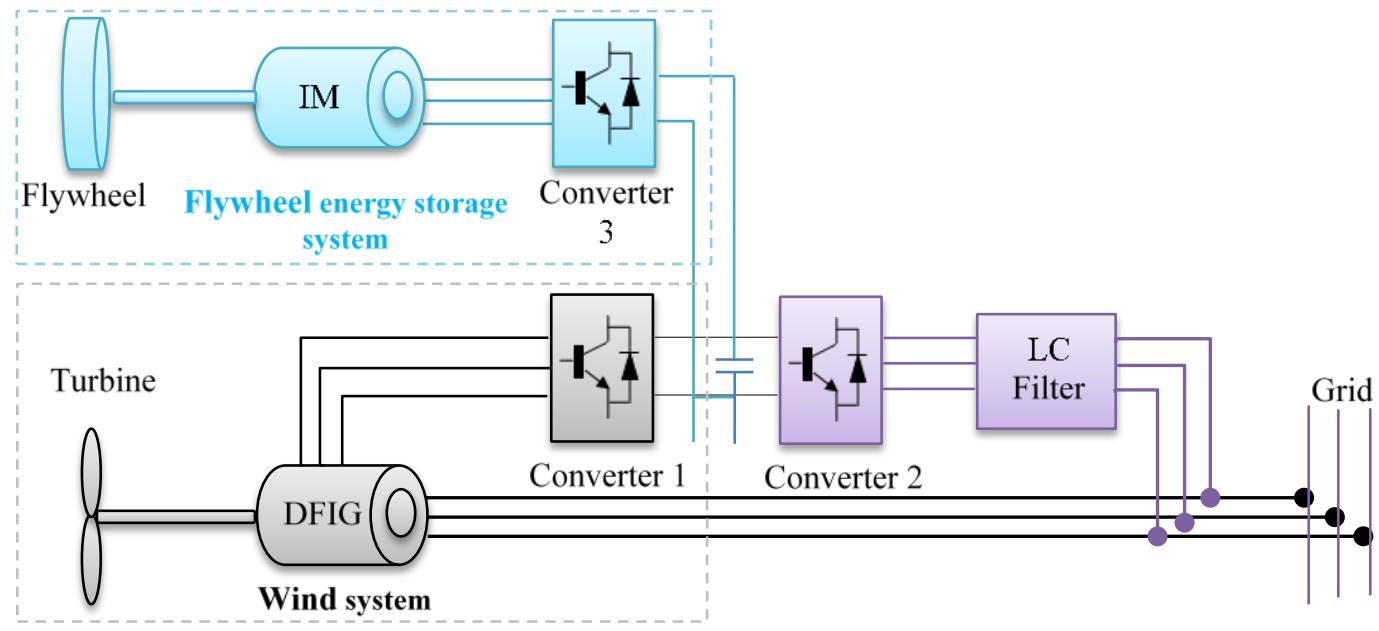

Figure 1. Wind system - FESS assembly under study

\section{FLYWHEEL ENERGY STORAGE SYSTEM}

\subsection{Flywheel modeling}

The FESS functions as an energy reserve which stocks the energy in kinetic shape in a rotating high speed mass that is coupled with the drive shaft of electric machine which supplies an electro-mechanical 
interface between the wheel and the system. While the charging operation, the machine works as a motor to accelerate the rotational movement of the flywheel and thus increase the stored energy, and then the flywheel stays in stand-by position. Whereas, on demand, the machine acts as a generator and slows down the wheel recuperating the stocked energy in the system [11]. To determine the flywheel inertia, we consider a required power during $\Delta \mathrm{t}$ time. Indeed, to stock the nominal power of the IM $\mathrm{P}_{\mathrm{n}-\mathrm{IM}}$ during $\Delta \mathrm{t}$, the energy $\Delta \mathrm{E}$ is then necessary such as [12]:

$$
\begin{aligned}
& \mathrm{E}_{\mathrm{f}}=\frac{1}{2} \mathrm{~J}_{\mathrm{f}} \Omega_{\mathrm{f}}^{2} \\
& \Delta \mathrm{E}_{\mathrm{f}}=\mathrm{P}_{\mathrm{n}-\mathrm{IM}} \Delta \mathrm{t}
\end{aligned}
$$

Combining (1) and (2), we define the necessary value of the flywheel inertia as [11]:

$$
\mathrm{J}_{\mathrm{f}}=\frac{2 \mathrm{P}_{\mathrm{n}-\mathrm{IM}} \Delta \mathrm{t}}{\Delta \Omega_{\mathrm{f}}^{2}}=\frac{2 \mathrm{P}_{\mathrm{n}-\mathrm{IM}} \Delta \mathrm{t}}{\Omega_{\mathrm{f} \max }^{2} \Omega_{\mathrm{f} \min }^{2}}
$$

$\Omega_{\mathrm{fmax}}$ and $\Omega_{\mathrm{fmin}}$ are the maximum and minimum speed limits of the flywheel, respectively. $\Delta t$ is then the time of storage. This limit should be respected; otherwise we may deteriorate the flywheel energy storage process.

\subsection{Mechanical shaft modeling}

The mechanical speed evolution of IM-based FESS can be easily calculated with the dynamic formula. The simplified model of this formula is described in [17]:

$$
\mathrm{J}_{\mathrm{f}} \frac{\mathrm{d} \Omega_{\mathrm{f}}}{\mathrm{dt}}=\mathrm{T}_{\mathrm{em}}-\mathrm{f} \Omega_{\mathrm{f}}
$$

$\mathrm{T}_{\mathrm{em}}(\mathrm{N} \cdot \mathrm{m})$ : electromagnetic torque, $\mathrm{f}(\mathrm{N} \cdot \mathrm{m} \cdot \mathrm{s} \cdot \mathrm{rad}-1)$ : viscous friction coefficient.

\subsection{IM modeling}

The IM is selected depending on these benefits in terms of simplicity and robustness of the rotative parts. The IM modelled in Park reference frame, is described by [15]:

$$
\left[\begin{array}{c}
\dot{\mathrm{x}}_{1} \\
\dot{\mathrm{x}}_{2} \\
\dot{\mathrm{x}}_{3} \\
\dot{\mathrm{x}}_{4} \\
\dot{\mathrm{x}}_{5}
\end{array}\right]=\left[\begin{array}{c}
-\gamma \cdot \mathrm{x}_{1}+\omega_{\mathrm{s}} \cdot \mathrm{x}_{2}+\frac{\mathrm{k}}{\mathrm{T}_{\mathrm{r}}} \mathrm{x}_{3}+\mathrm{px}_{5} \mathrm{kx}_{4} \\
-\omega_{\mathrm{s}} \mathrm{x}_{1}-\gamma \cdot \mathrm{x}_{2}-\mathrm{px}_{5} \mathrm{kx}_{3}+\frac{\mathrm{k}}{\mathrm{T}_{\mathrm{r}}} \mathrm{x}_{4} \\
\frac{\mathrm{M}}{\mathrm{T}_{\mathrm{r}}} \mathrm{x}_{1}-\frac{1}{\mathrm{~T}_{\mathrm{r}}} \mathrm{x}_{3}+\left(\omega_{\mathrm{s}}-\mathrm{px}_{5}\right) \mathrm{x}_{4} \\
\frac{\mathrm{M}}{\mathrm{T}_{\mathrm{r}}} \mathrm{x}_{2}-\left(\omega_{\mathrm{s}}-\mathrm{px}_{5}\right) \mathrm{x}_{3}-\frac{1}{\mathrm{~T}_{\mathrm{r}}} \mathrm{x}_{4} \\
\frac{\mathrm{pM}}{\mathrm{J} \mathrm{Lr}_{\mathrm{r}}}\left(\mathrm{x}_{2} \cdot \mathrm{x}_{3}-\mathrm{x}_{1} \mathrm{x}_{4}\right)-\frac{\mathrm{Cr}_{\mathrm{r}}}{\mathrm{J}}-\frac{\mathrm{f}}{\mathrm{J}} \mathrm{x}_{5}
\end{array}\right]+\left[\begin{array}{cc}
\frac{1}{\sigma \cdot \mathrm{L}_{\mathrm{s}}} & 0 \\
0 & \frac{1}{\sigma \cdot \mathrm{L}_{\mathrm{s}}} \\
0 & 0 \\
0 & 0 \\
0 & 0
\end{array}\right]\left[\begin{array}{c}
\mathrm{v}_{\mathrm{sd}} \\
\mathrm{v}_{\mathrm{sq}}
\end{array}\right]
$$

with $x=\left[i_{s d}, i_{s q}, \varphi_{r d}, \varphi_{r q}, \Omega\right]^{T}$

$$
\mathrm{k}=\frac{\mathrm{M}}{\sigma \mathrm{L}_{\mathrm{s}} \mathrm{L}_{\mathrm{r}}} \text { et } \gamma=\frac{\mathrm{R}_{\mathrm{s}}+\mathrm{R}_{\mathrm{r}} \frac{\mathrm{M}^{2}}{\mathrm{~L}_{\mathrm{r}}^{2}}}{\sigma \mathrm{L}_{\mathrm{s}}}, \sigma=1-\frac{\mathrm{M}^{2}}{\mathrm{~L}_{\mathrm{s}} \mathrm{L}_{\mathrm{r}}}, \mathrm{T}_{\mathrm{r}}=\mathrm{L}_{\mathrm{r}} / \mathrm{R}_{\mathrm{r}}
$$

\section{CONTROL STRATEGY FOR THE FESS}

\subsection{Field-oriented control for the FESS}

The reference model in the park, with the rotor flux orientation $\left(\varphi_{\mathrm{qr}}=0, \varphi_{\mathrm{dr}}=\varphi_{\mathrm{r}}\right)$ has the following equations [15]: 


$$
\left\{\begin{array}{c}
\frac{\mathrm{d}}{\mathrm{dt}} \mathrm{i}_{\mathrm{sd}}=-\gamma \mathrm{i}_{\mathrm{sd}}+\omega_{\mathrm{s}} \mathrm{i}_{\mathrm{sq}}+\frac{\mathrm{k}}{\mathrm{T}_{\mathrm{r}}} \varphi_{\mathrm{rd}}+\frac{1}{\sigma . \mathrm{L}_{\mathrm{s}}} \mathrm{v}_{\mathrm{sd}} \\
\frac{\mathrm{d}}{\mathrm{dt}} \mathrm{i}_{\mathrm{sq}}=-\gamma \mathrm{i}_{\mathrm{sq}}-\omega_{\mathrm{s}} \mathrm{i}_{\mathrm{sd}}-\mathrm{p} \Omega \mathrm{k} \varphi_{\mathrm{rd}}+\frac{1}{\sigma . \mathrm{L}_{\mathrm{s}}} \mathrm{v}_{\mathrm{sq}} \\
\frac{\mathrm{d}}{\mathrm{dt}} \varphi_{\mathrm{rd}}=\frac{\mathrm{M}}{\mathrm{T}_{\mathrm{r}}} \mathrm{i}_{\mathrm{sd}}-\frac{1}{\mathrm{~T}_{\mathrm{r}}} \varphi_{\mathrm{rd}} \\
\frac{\mathrm{d}}{\mathrm{dt}} \varphi_{\mathrm{rq}}=0=\frac{\mathrm{M}}{\mathrm{T}_{\mathrm{r}}} \mathrm{i}_{\mathrm{sq}}-\left(\omega_{\mathrm{s}}-\mathrm{p} \Omega\right) \varphi_{\mathrm{rd}} \\
\mathrm{J} \frac{\mathrm{d}}{\mathrm{dt}} \Omega=\mathrm{J} \frac{\mathrm{d}}{\mathrm{dt}} \Omega=\mathrm{p} \frac{\mathrm{M}}{\mathrm{L}_{\mathrm{r}}} \varphi_{\mathrm{rd}} \mathrm{i}_{\mathrm{sq}}-\mathrm{T}_{\mathrm{r}}-\mathrm{f} \Omega
\end{array}\right.
$$

The reference value of rotor flux is determined by the flux weakening algorithm. It is defined as [15]:

$$
\varphi_{\mathrm{r}-\mathrm{ref}}\left(\Omega_{\mathrm{f}}\right)=\left\{\begin{array}{c}
\varphi_{\mathrm{rn}} \text { if }\left|\Omega_{\mathrm{f}}\right| \leq \Omega_{\mathrm{fn}} \\
\varphi_{\mathrm{rn}} \cdot \frac{\Omega_{\mathrm{fn}}}{\left|\Omega_{\mathrm{f}}\right|} \text { if }\left|\Omega_{\mathrm{f}}\right|>\Omega_{\mathrm{fn}}
\end{array}\right.
$$

The FESS reference power $P_{f_{-} \text {ref }}$ should be restricted to the nominal value of IM power to avoid the overheating IM. The reference torque is indicated as follows:

$$
\mathrm{T}_{\mathrm{IM}-\mathrm{ref}}=\frac{\mathrm{P}_{\mathrm{f}-\mathrm{ref}}}{\Omega_{\mathrm{f}}}
$$

The quadratic reference current becomes:

$$
\mathrm{i}_{\mathrm{sq}-\mathrm{ref}}=\frac{\mathrm{T}_{\mathrm{IM}-\mathrm{ref}} \cdot \mathrm{L}_{\mathrm{r}-\mathrm{IM}}}{\text { P.M. } \varphi_{\mathrm{rd}-\mathrm{ref}}}
$$

The reference power exchanged between the storage system and the DC bus is given as follows:

$$
\mathrm{P}_{\mathrm{f}-\mathrm{ref}}=\mathrm{P}_{\mathrm{reg}}-\mathrm{P}_{\mathrm{wg}}+\Delta \mathrm{P}
$$

Where, $\mathrm{P}_{\text {reg }}$ the reference grid active power, and $\mathrm{P}_{\mathrm{wg}}$ the power generated by wind generator, $\Delta \mathrm{P}$ the power fluctuation on bus capacitor [17].

and, the kinetic energy $\mathrm{E}_{\text {cref }}$ is computed by the integration of (10) [11]:

$$
\mathrm{E}_{\text {cref }}=\int_{0}^{\mathrm{t}} \mathrm{P}_{\mathrm{f}_{-} r e f} \mathrm{dt}+\mathrm{E}_{\mathrm{c} 0}=\frac{1}{2} \mathrm{~J}_{\mathrm{f}} \Omega_{\mathrm{f}}^{2}
$$

where $E_{c 0}$ the initially kinetic of the storage system [11]. The flywheel speed reference is expressed as:

$$
\Omega_{\mathrm{ref}}=\sqrt{\frac{2 \mathrm{E}_{\mathrm{cref}}}{\mathrm{J}_{\mathrm{f}}}}
$$

\subsection{Fuzzy logic control for the FESS}

Figure 2 illustrates the block diagram of fuzzy controller, includes four parts: - Fuzzification knowledge rule base - fuzzy inference - Defuzzification [16-18].

The conception of the fuzzy logic controller begins by allocating the input and output variables. The more important variables entering the fuzzy logic speed controller where selected as the speed error and its temporal variation. Two inputs variables $\mathrm{E} \Omega(\mathrm{k})$ and $\mathrm{dE} \Omega(\mathrm{k})$, are computed at each sampling time [19]:

$$
\begin{aligned}
& \mathrm{E} \Omega(\mathrm{k})=\Omega_{\mathrm{f}-\mathrm{ref}}(\mathrm{k})-\Omega_{\mathrm{f}}(\mathrm{k}) \\
& \mathrm{d} \mathrm{E} \Omega(\mathrm{k})=\mathrm{E} \Omega(\mathrm{k})-\mathrm{E} \Omega(\mathrm{k}-1)
\end{aligned}
$$


Where $\mathrm{E} \Omega(\mathrm{k}-1)$ is the error value at the preceding sampling instant. The output variable of fuzzy logic speed controller is the varying control current $\operatorname{di}_{\mathrm{sq}_{\mathrm{ref}}}(\mathrm{k})$ that is incorporated to obtain the reference control current, $\mathrm{i}_{\mathrm{sq}_{\mathrm{ref}}}(\mathrm{k})$, as indicated in the next formula.

$$
\mathrm{i}_{\mathrm{sq}_{\mathrm{ref}}}(\mathrm{k})=\mathrm{i}_{\mathrm{sq}_{\mathrm{ref}}}(\mathrm{k}-1)+\mathrm{di}_{\mathrm{sq}_{\mathrm{ref}}}(\mathrm{k})
$$

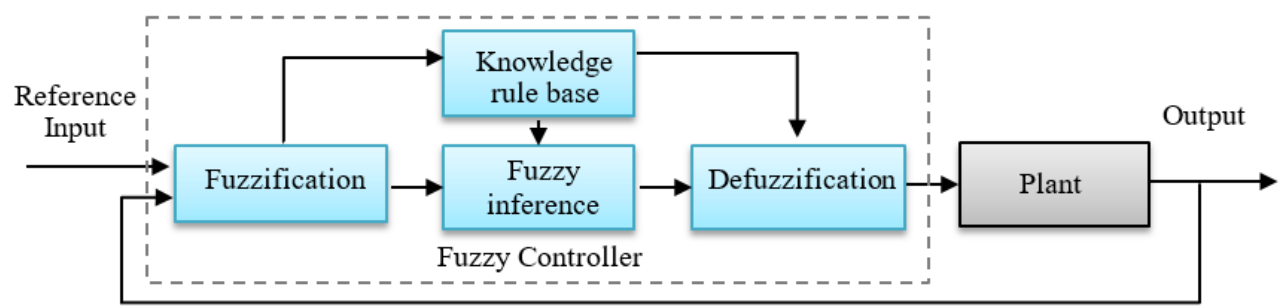

Figure 2. Fuzzy Control system scheme

\subsubsection{Fuzzification}

The quality of this step is critical to the success of this work. At this phase, the crisp variables $\mathrm{E} \Omega(\mathrm{k})$ and $\mathrm{dE} \Omega(\mathrm{k})$ are respectively transformed in to fuzzy variables $\mathrm{E} \Omega$ and $\mathrm{dE} \Omega$. Triangular fuzzy membership functions were defined as shown in Figure 3. The discourse universe of all input and output variables is set as $(-0.8,0.8)$. Appropriate scaling coefficients are selected to bring the input and output variables into this universe of discourse. Each discourse universe is split into seven overlapping fuzzy clusters: NL (Negative Large), NM (Negative Medium), NS (Negative Small), ZE (Zero), PS (Positive Small), PM (Positive Medium) and PL (Positive Large). Each fuzzy variable is a member of the subsets with a degree of membership $\mu$ ranging from 0 (non-member) to 1 (full member). All membership functions have an asymmetric shape with more clutter near the origin (stationary state). This allows a greater precision in the steady state [19].

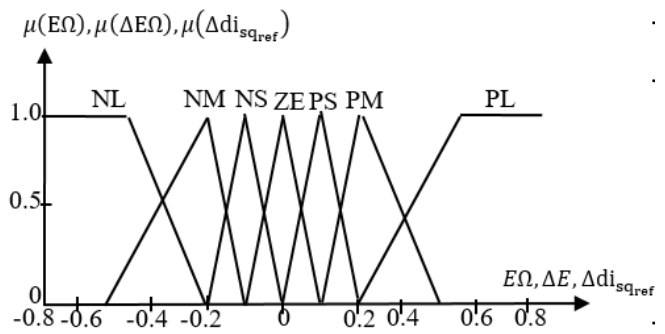

\begin{tabular}{clllllll}
\hline $\begin{array}{c}\text { E } \\
\mathrm{dE}\end{array}$ & NL & NM & NS & ZE & PS & PM & PL \\
\hline NL & NL & NL & NL & NL & NM & NS & ZE \\
NM & NL & NL & NL & NM & NS & ZE & PS \\
NS & NL & NL & NM & NS & ZE & PS & PM \\
ZE & NL & NM & NS & ZE & PS & PM & PL \\
PS & NM & NS & ZE & PS & PM & PL & PL \\
PM & NS & ZE & PS & PM & PL & PL & PL \\
PL & ZE & PS & PM & PL & PL & PL & PL \\
\hline
\end{tabular}

Figure 3. Membership inputs/outputs

\subsubsection{Knowledge base and Inference engine}

The fuzzy rules are expressed using the IF-THEN form as follows: if (input1 and input2) then output, in example: IF (E $\Omega$ is Positive Small) AND ( $\mathrm{dE} \Omega$ is Negative Medium) THEN ( $\mathrm{di}_{\mathrm{sq}_{\mathrm{ref}}}$ is Negative Small). TThe fuzzy variables $\mathrm{E} \Omega$ and $\mathrm{dE} \Omega$ are processed by an inference mechanism based on a set of control rules contained in $(7 * 7)$ table as shown in Table 1 . The crisp output of the FLC is obtained by using MAXMIN inference algorithm [19].

\subsubsection{Defuzzification}

In this step, a sharp value of the output variable $\operatorname{di}_{\text {sq }_{\mathrm{ref}}}(\mathrm{k})$ is determined through the defuzzification method, which first evaluates the centroid of every output membership feature for each rule. Then the final output is computed as the mean of the single centroids, which is weighted by their heights (degree of membership) as shown below: 
$\mathrm{di}_{\mathrm{sq}_{\mathrm{ref}}}(\mathrm{k})=\frac{\sum_{i=1}^{n} \mu\left[\left(\mathrm{di}_{\mathrm{sq}_{\mathrm{ref}}}\right)_{i}\right]\left(\mathrm{di}_{\mathrm{sq}_{\mathrm{ref}}}\right)_{i}}{\sum_{i=1}^{n} \mu\left[\left(\mathrm{di}_{\mathrm{sq}_{\mathrm{ref}}}\right)_{i}\right]}$

The control system scheme of the system is detailed in Figure 4.

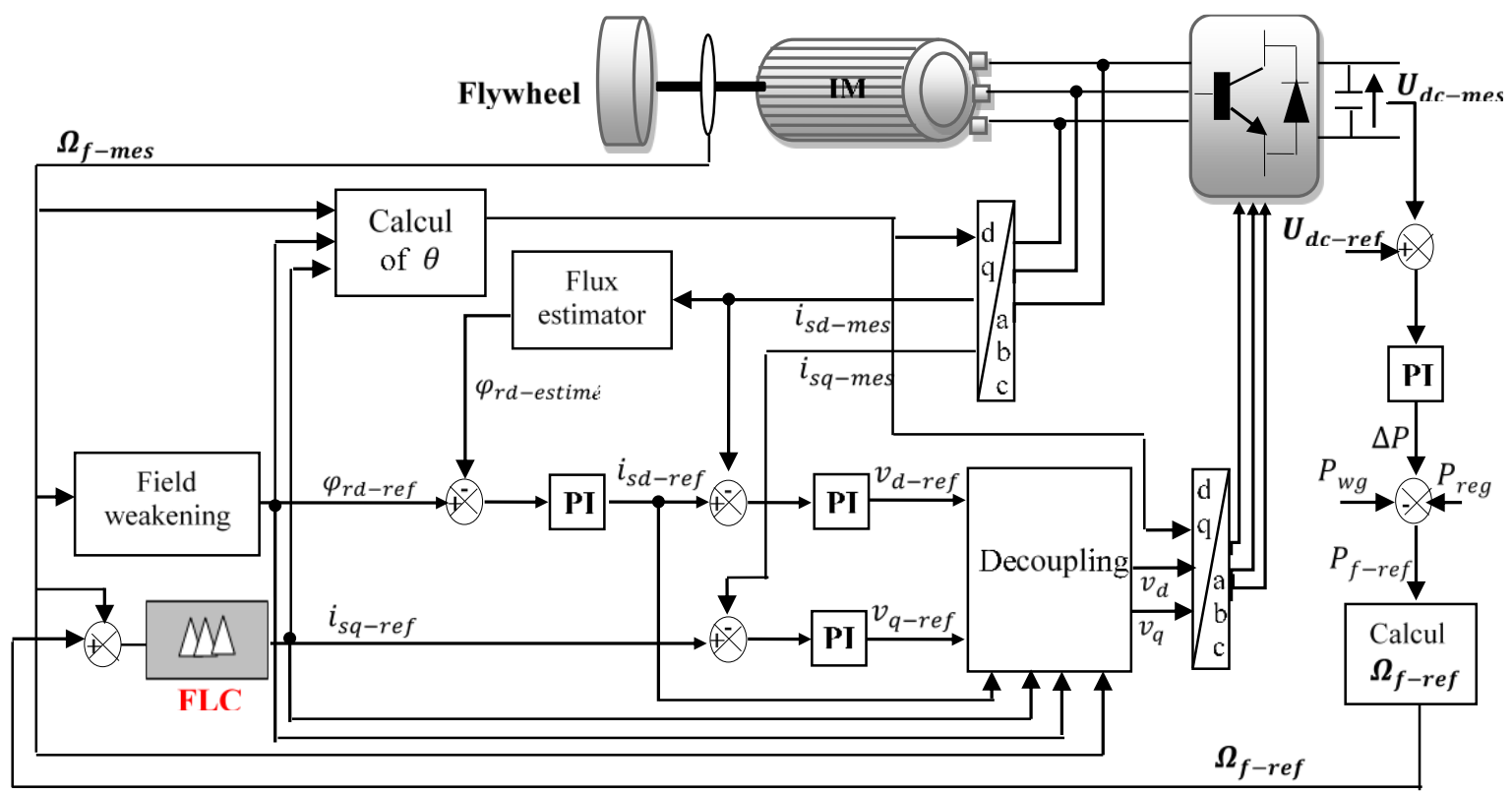

Figure 4. Fuzzy Control system of inertial storage scheme

\section{WIND TURBINE MODEL}

\subsection{Turbine modeling}

The modeling of a wind energy system is given by [20]:

$\left\{\begin{array}{c}P_{v}=\frac{\rho S v^{3}}{2} \\ P_{a e r}=\frac{C_{p}(\lambda, \beta) \rho S v^{3}}{2} \text { and } T_{a e r}=\frac{P_{a e r}}{\Omega_{t}}=\frac{C_{p}(\lambda, \beta) \rho S v^{3}}{2 \Omega_{t}}\end{array}\right.$

The Power coefficient $C_{p}$ dependent on the blade tilt angle $\beta$ and the tip speed ratio (TSR) $\lambda$ has the following definition [20, 21]:

$$
\left\{\begin{array}{c}
C_{p}(\lambda, \beta)=0.5176\left(\frac{116}{\lambda_{i}}-0.4 \beta-5\right) \mathrm{e}^{\frac{21}{-\lambda_{\mathrm{i}}}}+0.0068 \lambda \\
\lambda_{\mathrm{i}}=\frac{1}{\lambda+0.008 \beta}-\frac{0.035}{\beta^{3}+1} \text { and } \lambda=\frac{\Omega_{\mathrm{t}} \mathrm{R}}{\mathrm{v}}
\end{array}\right.
$$

Where $\mathrm{P}_{\mathrm{v}}, \mathrm{P}_{\mathrm{aer}}, \mathrm{T}_{\mathrm{aer}}, \rho, \mathrm{S}, \mathrm{R}, \Omega_{\mathrm{t}}$ and $\mathrm{v}$ are the turbine power, the aero-dynamic torque, the aerodensity $(\rho=1.22 \mathrm{~kg} / \mathrm{m} 3)$, the circular area swept by the turbine, the turbine radius, the turbine speed $(\mathrm{rad} / \mathrm{s})$ and the wind speed $(\mathrm{m} / \mathrm{s})$, respectively. The turbine is connected via a gearbox to the generator; the gearbox is modelised with these two equations [22]. Where: $\mathrm{T}_{\mathrm{mec}}$ is mechanical torque, $\Omega_{\mathrm{mec}}$ is the generator's speed, $\mathrm{G}$ is the ratio's gearbox.

$$
\left\{\begin{array}{l}
\mathrm{T}_{\mathrm{mec}}=\frac{\mathrm{T}_{\mathrm{tur}}}{\mathrm{G}} \\
\Omega_{\mathrm{mec}}=\mathrm{G} \cdot \Omega_{\mathrm{t}}
\end{array}\right.
$$


The basic dynamic equation of mechanical system on a shaft of the DFIG is as follows [20-22]: where:

$f$ : Coefficient of friction, $\mathrm{T}_{\mathrm{em}}$ : electro-magnetic torque.

$\mathrm{J} \frac{\mathrm{d} \Omega_{\mathrm{mec}}}{\mathrm{dt}}+\mathrm{f} . \Omega_{\mathrm{mec}}=\mathrm{T}_{\mathrm{mec}}-\mathrm{T}_{\mathrm{em}}$

\subsection{Model of doubly fed induction generator (DFIG)}

The Park state model of the generator is represented in the following matrix form [23, 24]:

$$
\left\{\begin{array} { l } 
{ \mathrm { V } _ { \mathrm { sd } } = \mathrm { R } _ { \mathrm { s } } \mathrm { i } _ { \mathrm { sd } } + \frac { \mathrm { d } } { \mathrm { dt } } \varphi _ { s d } - \omega _ { \mathrm { s } } \varphi _ { \mathrm { sq } } } \\
{ \mathrm { V } _ { \mathrm { sq } } = \mathrm { R } _ { \mathrm { s } } \mathrm { i } _ { \mathrm { sq } } + \frac { \mathrm { d } } { \mathrm { dt } } \varphi _ { \mathrm { sq } } + \omega _ { \mathrm { s } } \varphi _ { \mathrm { sd } } }
\end{array} \left\{\begin{array}{l}
\mathrm{V}_{\mathrm{rd}}=\mathrm{R}_{\mathrm{r}} \mathrm{i}_{\mathrm{rd}}+\frac{\mathrm{d}}{\mathrm{dt}} \varphi_{\mathrm{rd}}-\omega_{\mathrm{r}} \varphi_{\mathrm{rq}} \\
\mathrm{V}_{\mathrm{rq}}=\mathrm{R}_{\mathrm{r}} \mathrm{i}_{\mathrm{rq}}+\frac{\mathrm{d}}{\mathrm{dt}} \varphi_{\mathrm{rq}}-\omega_{\mathrm{r}} \varphi_{\mathrm{rd}}
\end{array}\right.\right.
$$

$R_{s}, R_{r}$ : stator and rotor phase resistances. $\omega_{s}=\omega+\omega_{r}$, and $\omega=P . \Omega_{m e c}$ is the electrical speed P is the pair pole number. The stator and rotor flux takes the following form:

$$
\left\{\begin{array} { l } 
{ \varphi _ { \mathrm { sd } } = \mathrm { L } _ { \mathrm { s } } \cdot \mathrm { i } _ { \mathrm { sd } } + \mathrm { M } \cdot \mathrm { i } _ { \mathrm { rd } } } \\
{ \varphi _ { \mathrm { sq } } = \mathrm { L } _ { \mathrm { s } } \cdot \mathrm { i } _ { \mathrm { sq } } + \mathrm { M } \cdot \mathrm { i } _ { \mathrm { rq } } }
\end{array} \left\{\begin{array}{l}
\varphi_{\mathrm{rd}}=\mathrm{L}_{\mathrm{r}} \cdot \mathrm{i}_{\mathrm{rd}}+\mathrm{M} \cdot \mathrm{I}_{\mathrm{sd}} \\
\varphi_{\mathrm{rq}}=\mathrm{L}_{\mathrm{r}} \cdot \mathrm{i}_{\mathrm{rq}}+\mathrm{M} \cdot \mathrm{I}_{\mathrm{sq}}
\end{array}\right.\right.
$$

In which, $\mathrm{i}_{\mathrm{sd}}, \mathrm{i}_{\mathrm{sq}} / \mathrm{i}_{\mathrm{rd}}, \mathrm{i}_{\mathrm{rq}}$ are d.q components of the stator and rotor currents, $\mathrm{L}_{\mathrm{s}}, \mathrm{L}_{\mathrm{r}}, \mathrm{M}$ : are stator, rotor and mutual inductances. The stator active and reactive power and the electro- magnetic torque of the DFIG takes the following form [23]:

$$
\begin{aligned}
& \left\{\begin{array}{l}
P_{\mathrm{s}}=\mathrm{V}_{\mathrm{sd}} \cdot \mathrm{i}_{\mathrm{sd}}+\mathrm{V}_{\mathrm{sq}} \cdot \mathrm{i}_{\mathrm{sq}} \\
Q_{\mathrm{s}}=\mathrm{V}_{\mathrm{sq}} \cdot \mathrm{i}_{\mathrm{sd}}-\mathrm{V}_{\mathrm{sd}} \cdot \mathrm{i}_{\mathrm{sq}}
\end{array}\right. \\
& \mathrm{T}_{\mathrm{em}}=\frac{3}{2} \mathrm{P} \frac{\mathrm{M}}{\mathrm{L}_{\mathrm{s}}}\left(\varphi_{\mathrm{sq}} \cdot \mathrm{i}_{\mathrm{rd}}-\varphi_{\mathrm{sd}} \cdot \mathrm{i}_{\mathrm{rq}}\right)
\end{aligned}
$$

To facilitate the control of electricity generation from wind, an independent control of active and reactive power will be achieved by developing the equations that relate the values of the rotor voltages generated by an inverter to the stator active and reactive power. [25]. Assuming a constant flux in the stator, we obtain:

$$
\begin{aligned}
& \left\{\begin{array}{l}
\mathrm{V}_{\mathrm{ds}}=0 \\
\mathrm{~V}_{\mathrm{qs}}=\mathrm{V}_{\mathrm{s}}
\end{array}\right. \\
& \left\{\begin{array}{l}
\mathrm{P}_{\mathrm{s}}=\mathrm{V}_{\mathrm{s}} \mathrm{i}_{\mathrm{qs}} \\
\mathrm{Q}_{\mathrm{s}}=\mathrm{V}_{\mathrm{s}} \mathrm{i}_{\mathrm{ds}}
\end{array}\right.
\end{aligned}
$$

The relationship between the rotoric and statoric currents is:

$$
\left\{\begin{array}{c}
\mathrm{i}_{\mathrm{ds}}=-\frac{\mathrm{M}}{\mathrm{L}_{\mathrm{s}}} \mathrm{i}_{\mathrm{dr}}+\frac{\varphi_{\mathrm{s}}}{\mathrm{L}_{\mathrm{s}}} \\
\mathrm{i}_{\mathrm{qs}}=-\frac{\mathrm{M}}{\mathrm{L}_{\mathrm{s}}} \mathrm{i}_{\mathrm{qr}}
\end{array}\right.
$$
by (27):

To obtain the expression of powers in function of stator currents, we substitute the currents in (26)

$$
\left\{\begin{array}{c}
P_{S}=-V_{s} \frac{M}{L_{s}} i_{q r} \\
Q_{s}=\frac{V_{s}^{2}}{L_{s} \omega_{s}}-\frac{V_{s} M}{L_{s}} i_{d r}
\end{array}\right.
$$

In order to correctly controlling the machine, we need to find the relationship between the rotor current and voltages: [26] 


$$
\left\{\begin{array}{c}
V_{d r}=R_{r} I_{d r}+\left(L_{r}-\frac{M^{2}}{L_{s}}\right) \frac{d I_{d r}}{d t}-g \omega_{s}\left(L_{r}-\frac{M^{2}}{L_{s}}\right) I q r \\
V_{q r}=R_{r} I_{q r}+\left(L_{r}-\frac{M^{2}}{L_{s}}\right) \frac{d I_{q r}}{d t}-g \omega_{s}\left(L_{r}-\frac{M^{2}}{L_{s}}\right) I_{d r}+g \frac{M v_{s}}{L_{s}}
\end{array}\right.
$$

Where $\mathrm{g}$ is the slip of the asynchronous machine. A complete DFIG model scheme is depicted in Figure 5.

\subsection{Indirect field oriented control (IFOC) of the DFIG}

To ensure stable functioning and to allow independent control of the active and reactive power of DFIG, a template-based PI regulator is constructed utilizing the dynamic equations. A schematic diagram is given in Figure 5 [25].

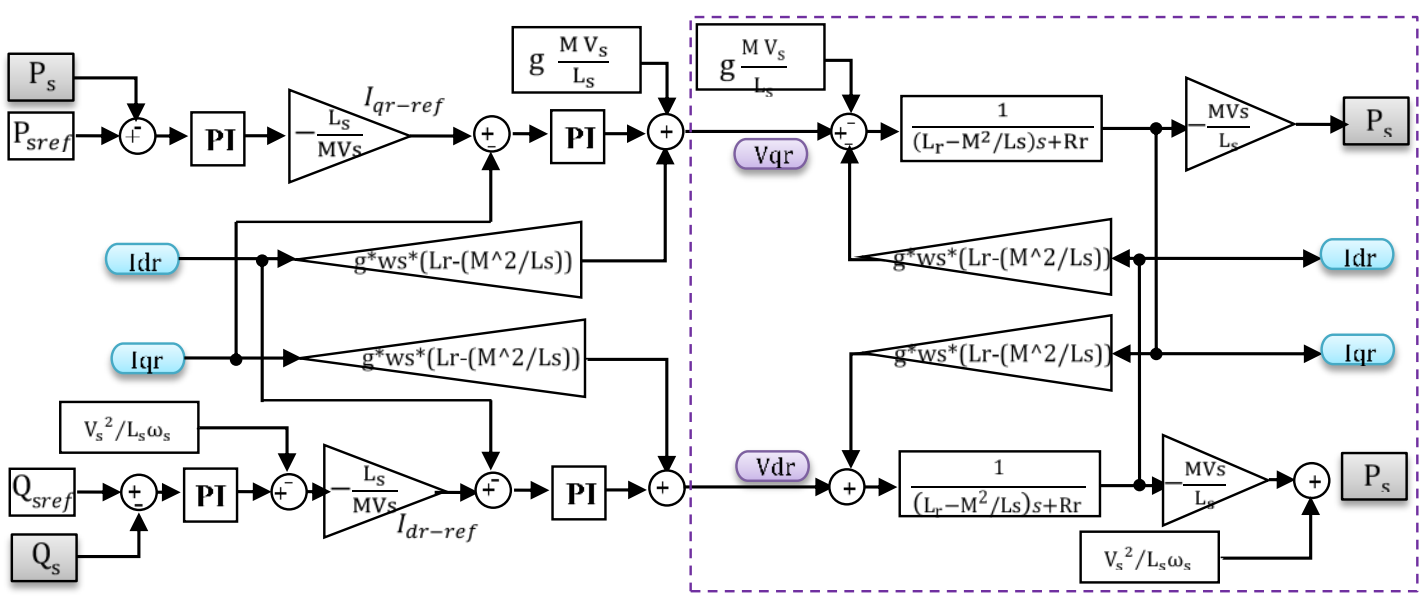

Figure 5. Control scheme of DFIG

\section{RESULTS AND ANALYSIS}

The parameters used can be found in Tables 2 and 3. The simulations were performed in Matlab / Simulink environment. Our aim is to show the behavior of the FESS on a charge/discharge cycles using speed control strategy. Figure 6 shows simulation results achieved by analysing the efficiency of FESS with IM. In this case, the FESS is not linked to the VSWG. Then, the flywheel decelerates and discharges its energy into the grid via the IM. At speed greater than $157 \mathrm{rad} / \mathrm{s}$, the IM connected to the flywheel functions in the field weakening zone. For $0<\mathrm{t}<1.5 \mathrm{~s}$ and $\mathrm{P}_{\mathrm{f}-\mathrm{ref}}>0$, the flywheel is accelerated to its maximum speed and stocks energy in the grid. It functions in motor operation. However, for $1.5<\mathrm{t}<3 \mathrm{~s}$ and $\mathrm{P}_{\mathrm{f}-\mathrm{ref}}<0$, the flywheel decelerates and runs in generator mode. To test the robustness of the parametric fuzzy controller, we performed a parametric variation of the machine and studied the influence on the performance of the speed control and its power comportement. The variation is plotted on the rotor resistance $\mathrm{Rr}(50 \%$ increase of $\mathrm{Rr}$ ). The results achieved Figure 7, indicate that the variation of the rotor resistance influences the decoupling of the system for PI regulator; however, the fuzzy control almost keeps the original performance despite the variation of parameter in question. The simulation of the indirect field oriented control of a DFIG-based wind system is represented in Figure 8. This figure demonstrates that our system has satisfactory dynamic, the active and reactive powers of the stator follow their references almost perfectly and provide a perfect decoupling between both axes.

Table 2. FESS Parameters

\begin{tabular}{ccc}
\hline $\mathbf{P}=\mathbf{2}$ & $\mathbf{R}_{\mathrm{s}}=\mathbf{4 . 8 5} \Omega$ & $\mathbf{R}_{\mathbf{r}}=\mathbf{3 . 8 0 5} \Omega$ \\
\hline $\mathbf{L}_{\mathrm{s}}=\mathbf{0 . 2 7 4} \mathbf{H}$ & $\mathrm{L}_{\mathrm{rr}}=0.27 \mathrm{Hen}$ & $\mathrm{M}=0.25 \mathrm{Hen}$ \\
\hline $\mathbf{J}_{\mathrm{f}}=\mathbf{2 0 . 2 8 \mathbf { ~ m } ^ { 2 } \mathbf { k g }}$ & $\mathrm{f}_{\mathrm{f}}=0.022 \mathrm{Nm} / \mathrm{s}$ & \\
\hline
\end{tabular}

Table 3. DFIG and Turbine Parameters

\begin{tabular}{lcc}
\hline $\mathbf{P}_{\mathbf{n}}=10 \mathrm{KW}$ & $\mathbf{R}_{\mathbf{s}}=\mathbf{0 . 4 5 5} \Omega$ & $\mathrm{G}=90$ \\
\hline $\mathbf{R}_{\mathbf{r}}=\mathbf{0 . 1 9 0} \Omega$ & $\mathrm{L}_{\mathrm{s}}=0.070 \mathrm{H}$ & $\mathrm{R}=35 \mathrm{~m}$ \\
\hline $\mathbf{L}_{\mathbf{r}}=\mathbf{0 . 0 2 1 3 H}$ & $\mathrm{M}=0.034 \mathrm{H}$ & $\mathrm{N}=3$ \\
\hline
\end{tabular}

In what follows, we passed to FESS - VSWG connection in order to regulate the electrical power generated by the wind. All simulations are run with the same wind profile as shown in Figure 9 . The rated 
power of the DFIG is $10 \mathrm{KW}$ and the IM was rated at $3 \mathrm{~kW}$ at $1500 \mathrm{Tr} / \mathrm{mn}$, the variable power of the wind turbine and the desired grid power (fixed to $-2.2 \mathrm{kw}$ ) are shown in Figure 10. Figure 11 shows the power transmission between the FESS and the grid, i.e power storage of the inertial system (FESS). The flow direction of this power fluctuates as a function of the power generated by the wind turbine. If the latter is less than $-2.2 \mathrm{KW}$, the power transfer from the network to the SISE (storage); if not, from the SISE to the network (destocking) to offset for the power deficit of the wind. A rotational speed increases when the energy is transferred to the FESS, and decreases when the energy is transferred to the grid. Figure 12 shows the electro-magnetic torque of the IM which is fluctuant; it depends directly on the electrical power of the FESS, which is reflected in its shape identical to that of the power of the FESS. The direct and quadrature rotor flux elements of the IM are also depicted in Figure 12. The quadrature component is always zero, justifying the rotor flux-oriented control.
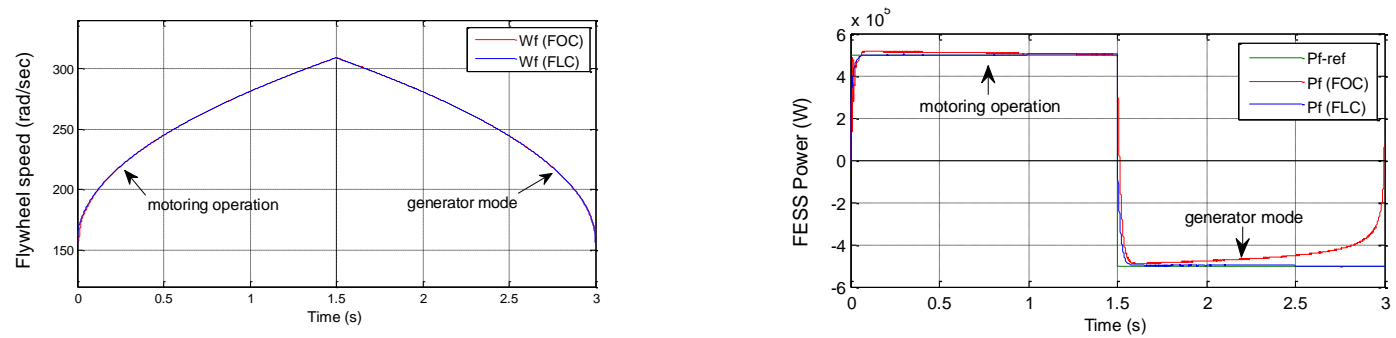

Figure 6. Speed and power responses of IM/flywheel system
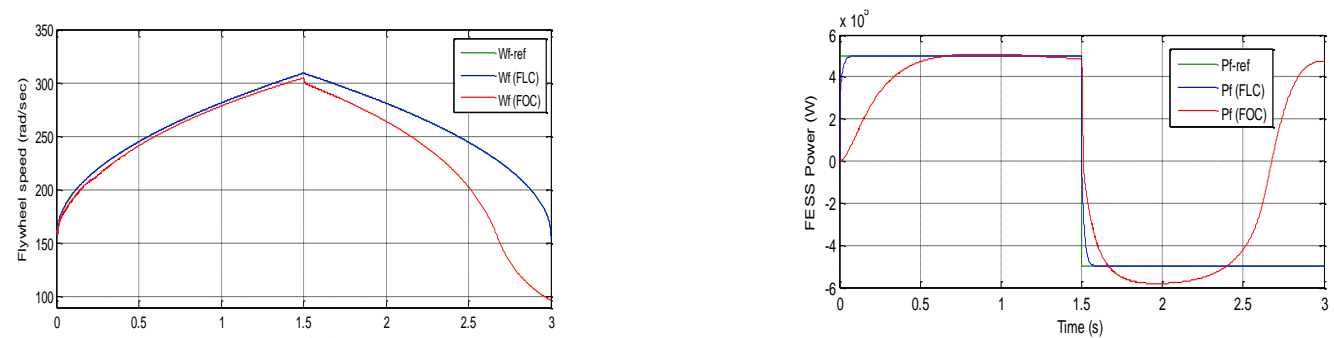

Figure 7. Test of robustness with parameter variations
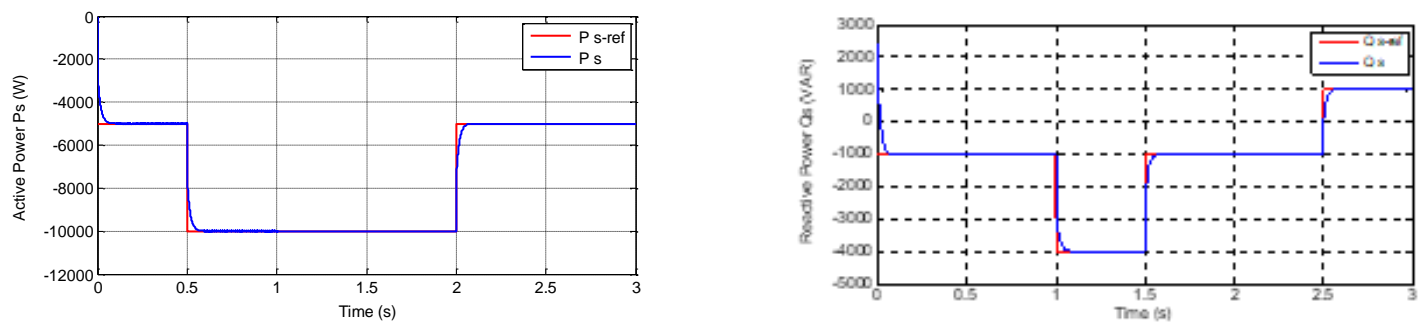

Figure 8. Stator active and reactive power control of DFIG

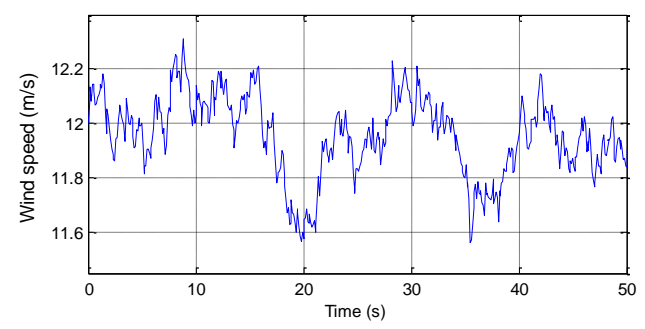

Figure 9. Wind speed

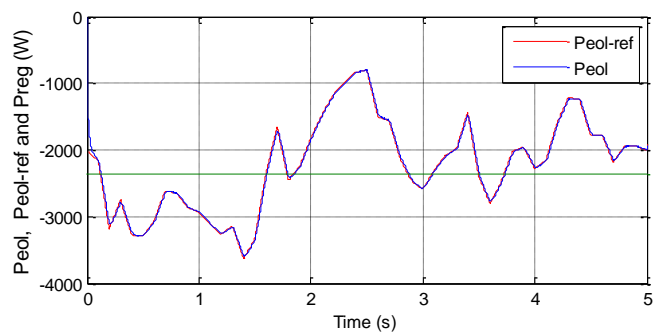

Figure 10. Power generated by the DFIG 

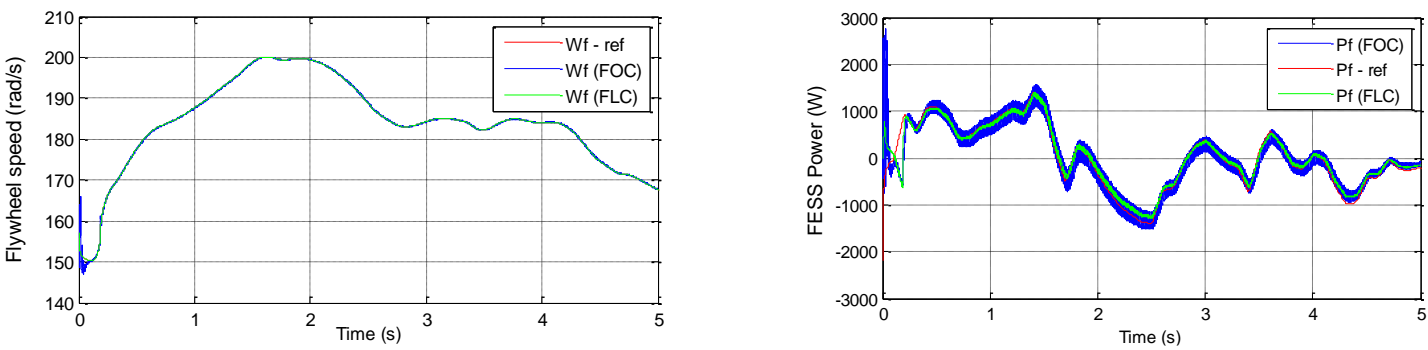

Figure 11. Simulation of the VSWG-FESS assembly
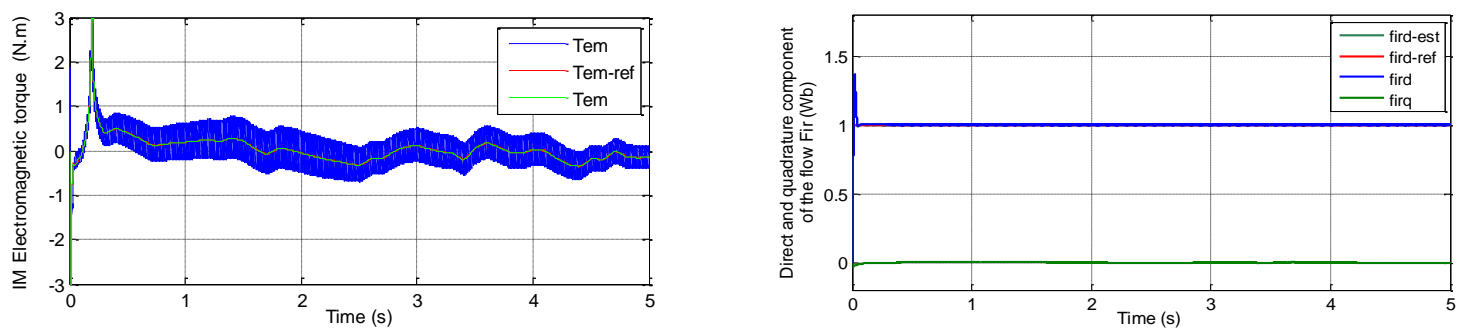

Figure 12. Electromagnetic torque and rotor flux of the IM

The comparison between both controls reveals several benefits of the fuzzy logic controller, such as robustness and better reference tracking compared to the flux oriented control. In the paper [14], it is apparent that the FESS power exhibits frequent oscillations, implying a lower robustness. When comparing these results with ours, we find that the Flywheel energy storage system in our study is more reliably and robust, which allows for better energy injection into the network.

\section{CONCLUSION}

The research reported in this paper is focused on the analysis, modelling and simulation of a variable speed wind turbine using a double-fed induction machine in combination with a flywheel storage system in the aim to resolve the problem of fluctuating power output. Two FESS supervision strategies namely FOC and FLC have been applied. It has been noted that the FLC is a preferable choice for such application. The simulation results displayed prove that a correctly functioning of the storage system is in place, in effect, the measured power exactly tracks the reference power. The good control effect is proved by the simulation results. The process of charging and discharging are stable and the control objectives are achieved.

\section{REFERENCES}

[1] H. Zhao, Q. Wu, S. Hu, H. Xu, and C. N. Rasmussen. "Review of energy storage system for wind power integration support." Applied Energy, vol. 137, pp. 545-553, Jan 2015.

[2] F. Nadeem, S. M. S. Hussain, P. Tiwari, A. Goswami, and T. S. Ustun. "Comparative Review of Energy Storage Systems, Their Roles, and Impacts on Future Power Systems.” IEEE Access, vol. 7, pp. 4555- 4585, Jan 2019.

[3] V. Neisch, R. Klar and M. Aufleger. "Development of hydraulic energy storage systems for decentralized applications." Proceedings of the International Conference and Exhibition (Hydro 2013), Oct 2013.

[4] T. S. Mathis, N. Kurra, X. Wang, D. Pinto, P. Simon, and Y. Gogotsi. "Energy Storage Data Reporting in Perspective-Guidelines for Interpreting the Performance of Electrochemical Energy Storage Systems." Adv. Energy Mater, Sep 2019.

[5] J. Wang, K. Lu, L. Ma, J. Wang, M. Dooner, S. Miao, J. Li and D. Wang. "Overview of Compressed Air Energy Storage and Technology Development." Energies, vol. 10, no. 7, p. 991, 2017.

[6] A. Kumar Sahoo, N. Mohanty, M. Anupriya. "Modeling and Simulation of Superconducting Magnetic Energy Storage Systems." International Journal of Power Electronics and Drive System (IJPEDS), vol. 6, No.3, pp. 524 537, Sep 2015.

[7] K. Sahay, and B. Dwivedi. "Supercapacitors Energy Storage System for Power Quality Improvement." J. Electrical Systems, vol, 5, no. 4, 2009. 
[8] A.A. Khodadoost Arania, H. Karamia, G.B. Gharehpetiana, and M.S.A. Hejazib, "Review of Flywheel Energy Storage Systems structures and applications in power systems and microgrids," Renewable and Sustainable Energy Reviews, vol. 69, pp. 9- 18, Nov 2016.

[9] M. E. Amiryar, K. R. Pullen. "A Review of Flywheel Energy Storage System Technologies and Their Applications." Applied. Science, vol. 7, no. 3, p. 286, 2017.

[10] M. Khaterchi, J. Belhadj, M. Elleuch. "Participation of Direct Drive Wind Turbine To The Grid Ancillary Services Using A Flywheel Energy Storage System." 7th International Multi-Conference on Systems, Signals and Devices, pp. 1-6, 2010.

[11] M. Nadour, A. Essadki, T. Nasser, and M. Fdaili, "Robust coordinated control using backstepping of flywheel energy storage system and DFIG for power smoothing in wind power plants," International Journal of Power Electronics and Drive System (IJPEDS), vol.10, No. 2, pp. 1110 1122, Jun 2019.

[12] M. Mansour, S. Rachdi, M. N. Mansouri, and M. F. Mimouni. "Direct Torque Control Strategy of an InductionMachine-Based Flywheel Energy Storage System Associated to a Variable-Speed Wind Generator.” Energy and Power Engineering, vol. 4, pp. 255-263, Jul 2012.

[13] G. O. Cimuca, C. Saudemont, B. Robyns, and M. M. Radulescu. "Control and performance evaluation of a flywheel energy-storage system associated to a variable-speed wind generator." IEEE Trans. Ind. Electron, vol. 53, pp. 1074-1085, 2006.

[14] S. Belfedhal, S. Kouadria, E. M. Berkouk, and Y. Messlem. "Flywheel Energy Storage System with Induction Machine Associated to a Variable-Speed Wind Generator." IEEE, Eighth International Conference and Exhibition on Ecological Vehicles and Renewable Energies (EVER), Monte carlo, Monaco, May 2013.

[15] S. Belfedhal, E. M. Berkouk. "Modeling and Control of Wind Power Conversion System with a Flywheel Energy Storage System.” International Journal Of Renewable Energy Research, (IJRER), Vol.1, No. 3, pp. 43-52 ,2011

[16] A. H. Ahmed, A. B. Kotb, and A. M. Ali. "Comparison between Fuzzy Logic and PI Control for the Speed of BLDC Motor." International Journal of Power Electronics and Drive System (IJPEDS), vol.9, No. 3, pp. 1116 1123, Sep 2018.

[17] M. Mansour, M. N. Mansouri, and M. F. Mimouni. "Modeling and Control of IM-based Flywheel Energy-Storage System Associated to a Variable-Speed Wind Generator." 2ème conférence Internationale des énergies renouvelables CIER-2014.

[18] S. Kumar, D. Roy, and M. Singh. "A fuzzy logic controller based brushless DC motor using PFC cuk converter." International Journal of Power Electronics and Drive System (IJPEDS), vol.10, No. 4, pp. 1894 1905, Dec 2019.

[19] P. Tripura, and Y. Srinivasa Kishore Babu, "Fuzzy Logic Speed Control of Three Phase Induction Motor Drive," World Academy of Science, Engineering and Technology, vol.5, No. 12, pp. 1894 1905, 2011.

[20] S. Mensou, A. Essadki, I. Minka, T. Nasser, B. B. Idrissi, and L. B. Tarla, " Performance of a vector control for DFIG driven by wind turbine: real time simulation using DS1104 controller board," International Journal of Power Electronics and Drive System (IJPEDS), vol.10, No. 2, pp. 1003 1013, Jun 2019.

[21] I. Yasmine, E. B. Chakib, and B. Badre. "Improved Performance of DFIG-generators for Wind Turbines Variablespeed." International Journal of Power Electronics and Drive System (IJPEDS), vol.9, No. 4, pp. 1875 1890, Dec 2018.

[22] F. Senani, A. Rahab, and H. Benalla. "A Complete Modeling and Control for Wind Turbine Based of a Doubly Fed Induction Generator using Direct Power Control." International Journal of Power Electronics and Drive System (IJPEDS), vol.8, No. 4, pp. 1954 1962, Dec 2017.

[23] K. Belgacem, A. Mezouar, and N. Essounbouli. "Design and Analysis of Adaptive Sliding Mode with Exponential Reaching Law Control for Double-Fed Induction Generator Based Wind Turbine." International Journal of Power Electronics and Drive System (IJPEDS), vol.9, No. 4, pp. 1534 1544, Dec 2018.

[24] M. Benmeziane, S. Zebirate, A. Chaker and Z. Boudjema. "Fuzzy sliding mode control of doubly-fed induction generator driven by wind turbine." International Journal of Power Electronics and Drive System (IJPEDS), vol.10, No. 3, pp. 1592 1602, Sep 2019.

[25] I. El Karaoui, M. Maaroufi, and B. Bossoufi. "Robust power control methods for wind turbines using DFIGgenerator." International Journal of Power Electronics and Drive System (IJPEDS), vol.10, No. 4, pp. 2101 2117, Dec 2019. 